\title{
Meta-analysis of subxiphoid approach versus lateral approach for thoracoscopic Thymectomy
}

\author{
Jiaduo Li ${ }^{1}$, Guoyan $\mathrm{Qi}^{1^{*}}$ D, Yaling Liu², Xuguang Zheng ${ }^{1}$ and Xiaohe Zhang ${ }^{1}$
}

\begin{abstract}
Background: Compared with traditional open surgery for thymectomy, video-assisted thoracoscopic surgery (VATS) reduces hospital stay, decreases postoperative pain, and recovers faster. VATS has become increasingly popular in the past decade. VATS techniques to perform a thymectomy include subxiphoid video-assisted thoracoscopic surgery (SVATS) or lateral video-assisted thoracoscopic surgery (LVATS). In this study, our objective was to systematically review on VATS thymectomy and draw a meta-analysis on the outcomes between the two approaches.

Methods: We searched online databases and identified studies from database inception to 2019 that compared SVATS to LVATS thymectomy. Study endpoints included operative time, operative blood loss, length of hospital stay, postoperative pleural drainage, postoperative complications, conversion to open, oncologic outcomes.

Results: Four hundred seventy-one patients were included in this study, for which 200 and 271 patients underwent SVATS and LVATS thymectomy, respectively. Patients in the SVATS group had significantly less operative time, operative blood loss, length of hospital stay, and postoperative complications were identified. There was no statistical difference in postoperative pleural drainage, conversion to open and oncologic outcomes. No hospital deaths were recorded for either procedure.

Conclusions: While randomized controlled studies are required to make definitive conclusions, this meta-analysis suggests that SVATS thymectomy is safe and can achieve good and safe operative and perioperative outcomes similar or better to LVATS thymectomy.
\end{abstract}

Keywords: VATS, Subxiphoid, Lateral approach, Thoracoscopic thymectomy

\section{Introduction}

Thymectomy is one of the most important treatments for patients with myasthenia gravis (MG) or thymoma. In recent years, the development of surgical techniques has led to the rapid development of surgical approaches to thymectomy. Now, VATS thymectomy through the intercostal approach has been the commonly used

\footnotetext{
*Correspondence: guoyanqi2019@163.com

'Center of Treatment of Myasthenia Gravis Hebei Province, First Hospital of Shijiazhuang, Fangbei road No. 9, Shijiazhuang 050011, Hebei Province, China

Full list of author information is available at the end of the article
}

minimally invasive surgical procedure for thymus surgery and is applied worldwide [1-4]. SVATS is a newer alternative to LVATS and current research suggests that subxiphoid thoracoscopic thymectomy leads to less invasive than the lateral approach [5-9]. However, many surgeons remain reluctant to adopt SVATS surgical techniques for the treatment of patients with myasthenia gravis and thymomas for several reasons. The choice of SVATS or LVATS thymectomy remains controversial. There were no systematic reviews and meta-analysis to compare SVATS thymectomy with LVATS thymectomy.

(c) The Author(s). 2020 Open Access This article is licensed under a Creative Commons Attribution 4.0 International License, which permits use, sharing, adaptation, distribution and reproduction in any medium or format, as long as you give appropriate credit to the original author(s) and the source, provide a link to the Creative Commons licence, and indicate if changes were made. The images or other third party material in this article are included in the article's Creative Commons licence, unless indicated otherwise in a credit line to the material. If material is not included in the article's Creative Commons licence and your intended use is not permitted by statutory regulation or exceeds the permitted use, you will need to obtain permission directly from the copyright holder. To view a copy of this licence, visit http://creativecommons.org/licenses/by/4.0/ The Creative Commons Public Domain Dedication waiver (http://creativecommons.org/publicdomain/zero/1.0/) applies to the data made available in this article, unless otherwise stated in a credit line to the data. 
The purpose of this study was to determine whether SVATS thymectomy is a better approach to the operative and perioperative outcomes. We systematically identified and evaluated the existing data comparing the clinical outcomes of SVTAS thymectomy to LVATS thymectomy by using the techniques of meta-analysis.

\section{Methods}

\section{Search strategy}

Electronic database searches were performed with PubMed, Ovid Medline, Scopus, and Google Scholar of Abstract of Review of Effectiveness from database inception to Nov 2019. We used medical subject headings $(\mathrm{MeSH})$ and free-text words. Search terms used included the following: thymectomy $(\mathrm{MeSH})$, myasthenia gravis $(\mathrm{MeSH})$, thymoma $(\mathrm{MeSH})$, thymus gland $(\mathrm{MeSH})$, thoracic surgery, video-assisted (MeSH), thoracoscopy $(\mathrm{MeSH})$, subxiphoid, lateral, right and left. Only English language papers were included.

To achieve maximum sensitivity, all search terms were combined with Boolean operators and searched as both keywords and $\mathrm{MeSH}$ terms. After exclusion of articles based on title or abstract, full-text articles selected had reference lists searched for any potential further articles to be included in this review.

\section{Study selection}

Inclusion criteria were met if: (I) the English language journal article described VATS thymectomy, (II) Randomized clinical trials (RCTs) or non-randomized controlled studies or observational studies (with at least 10 patients undergoing each intervention), comparing the subxiphoid approach with lateral approach for thoracoscopic thymectomy.

Exclusion criteria were met if: (I) publication was not in English, (II) publication was not a journal article (book, book chapter), (III) publication was not about VATS thymectomy, (IV) publication was a health technology assessment that was not published in a peerreviewed journal, (V) study was a review, (VI) publication did not have a comparator, (VII) publication was about da Vinci thymectomy, (VIII) the study did not provide quantitative results for at least one of the findings relative to the outcomes of interest. The PRISMA flowchart is outlined in Fig. 1.

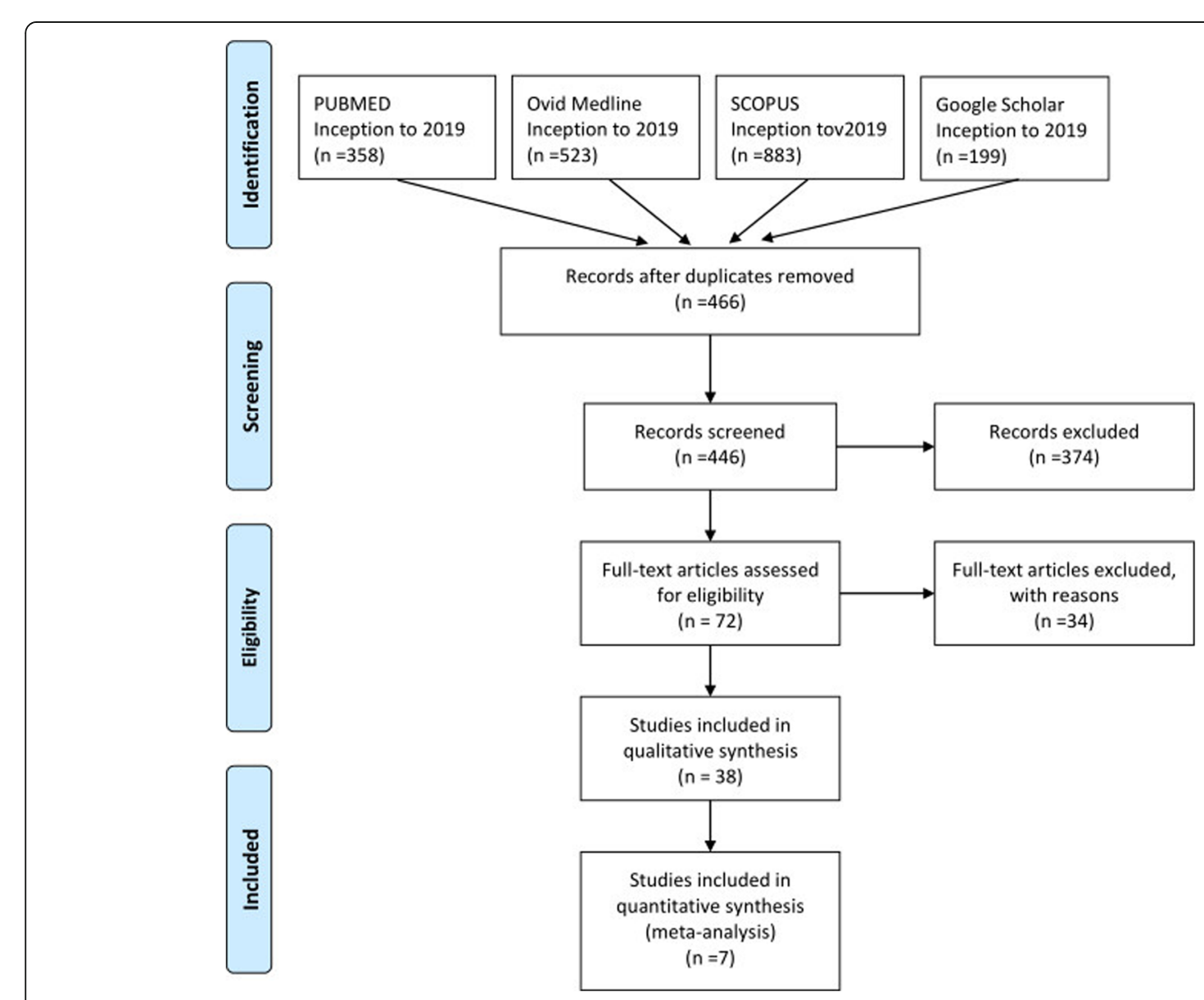

Fig. 1 Flow diagram for study selection 
Table 1 Summary of Study Demographics

\begin{tabular}{|c|c|c|c|c|c|c|c|c|c|c|}
\hline \multirow[t]{2}{*}{ Author } & No. & No. & No. Male & No. Male & Mean \pm SD & Mean \pm SD & No. Myasthenia & No. Myasthenia & No. Thymoma & No. Thymoma \\
\hline & SVATS & LVATS & SVATS & LVATS & Age SVATS & Age LVATS & Gravis SVATS & Gravis LVATS & SVATS & LVATS \\
\hline Suda Takashi & 46 & 35 & 23 & 15 & $53.9 \pm 14.4$ & $49.7 \pm 17.8$ & 11 & 10 & 11 & 27 \\
\hline Hsu C-P & 15 & 12 & 5 & 7 & $41.2(23-80)$ & $39.3(27-62)$ & 15 & 12 & 4 & 2 \\
\hline Wang, $\mathrm{H}$ & 36 & 47 & NA & NA & NA & NA & 0 & 0 & 36 & 47 \\
\hline Yano Motoki & 14 & 46 & 7 & 20 & 48(18-79) & $58(13-87)$ & 1 & 2 & 7 & 26 \\
\hline Lu Qiang & 41 & 36 & 16 & 13 & $36.3 \pm 8.2$ & $38.5 \pm 9.1$ & 1 & 2 & 10 & 12 \\
\hline Zhang ouqian & 28 & 70 & 16 & 26 & $58.2 \pm 10$ & $54.8 \pm 8.6$ & 0 & 0 & 28 & 70 \\
\hline Yong Tang & 20 & 25 & NA & NA & NA & NA & NA & NA & NA & NA \\
\hline
\end{tabular}

NA, not available

\section{.Quality evaluation}

We applied the Newcastle-Ottawa scale (NOS) [5] to evaluate the qualities of the included studies. A "star system" was used to judge the data quality of these studies based on three broad categories: the selection, the comparability, and the outcome or exposure of interest. The stars were summed to compare the quality of a study in a quantitative fashion. The scores ranged from 0 to 9 stars. Studies with scores of 6 stars or greater were considered to be of highquality studies. Two reviewers (Yaling Liu and Jiaduo li) independently evaluated and cross-checked the qualities of the included studies, and assessed the bias of the studies. An open discussion was held to confirm the scores of those studies that received a different score from each reviewer.

\section{Data extraction}

One investigator independently reviewed each included article under the guidance of two faculty members from the same center. Study endpoints included some or all of the following: age (years), gender, approach (subxiphoid or lateral), mean operative time (minutes), mean operative blood loss (milliliters $[\mathrm{mL}]$ ), converted to open, postoperative pleural drainage (days), postoperative complication, length of hospital stay (days), oncologic outcomes.

\section{Statistical analysis}

Conventional descriptive statistics were used to summarize the baseline demographics of the included patients. Data were presented as raw numbers, percentages, or means with standard deviations unless otherwise indicated. For dichotomous data (eg, incidence of complications), we used both a fixed and random effects model to calculate a pooled RR. For continuous data (eg, mean operating time), we used both a fixed and random effects model to calculate a weighted MD (WMD). In the case of continuous data presented as median and range, we estimated the mean and standard deviation according to the method described by Higgins $[6,7]$. Heterogeneity was investigated by the use of the X2 test and I2 statistics. For I2 of between 0 and 25\%, heterogeneity was considered as probably not important, between 25 and 50\% moderate, between 50 and $90 \%$ (or if the $P$-value of X2 was <0.10) substantial, and between 75 and 100\% considerable [8]. If heterogeneity existed ( $>25 \%$ ), we analyzed data using a random-effects model. If heterogeneity was not important, a fixed-effects model was used. $P<0.05$ was considered statistically significant.

All statistical analyses were performed by using Stata Statistical Software (Version 11.0; StataCorp LP, Texas, USA).

Table 2 Operative Outcomes for Thymectomy

\begin{tabular}{|c|c|c|c|c|c|c|}
\hline \multirow[t]{2}{*}{ Author } & $\begin{array}{l}\text { Mean } \pm \text { SD } \\
\text { Operation Time }\end{array}$ & $\begin{array}{l}\text { Mean } \pm \text { SD } \\
\text { Operation Time }\end{array}$ & $\begin{array}{l}\text { Mean } \pm \text { SD } \\
\text { Blood Loss }\end{array}$ & $\begin{array}{l}\text { Mean } \pm \text { SD } \\
\text { Blood Loss }\end{array}$ & No. Converted to Open & No. Converted to Open \\
\hline & SVATS, min & LVATS, min & SVATS, ml & LVATS, ml & SVATS & LVATS \\
\hline Suda Takashi & $140.3 \pm 50.5$ & $160.0 \pm 57.2$ & $2.2 \pm 0.8$ & $23.1 \pm 22$ & 0 & 0 \\
\hline Hsu C-P & $151.3 \pm 23.2$ & $171.5 \pm 32.1$ & NA & NA & 0 & 0 \\
\hline Wang, $\mathrm{H}$ & $54 \pm 16$ & $65 \pm 18$ & $51 \pm 34$ & $53 \pm 44$ & 2 & 2 \\
\hline Yano Motoki & $154 \pm 104$ & $200 \pm 119$ & $89 \pm 316$ & $42 \pm 80$ & 0 & 0 \\
\hline Lu Qiang & $95.3 \pm 25.5$ & $120 \pm 24.6$ & $25.5 \pm 10.6$ & $55.1 \pm 10.4$ & 2 & 4 \\
\hline Zhang Louqian & $104 \pm 29$ & $116 \pm 36$ & $46.6 \pm 30.9$ & $50 \pm 38.6$ & 0 & 0 \\
\hline Yong Tang & $136.1 \pm 51.7$ & $139.5 \pm 39.7$ & $66.5 \pm 42.8$ & $138.8 \pm 123$ & NA & NA \\
\hline
\end{tabular}


Table 3 In-Hospital Postoperative Outcomes

\begin{tabular}{|c|c|c|c|c|c|c|}
\hline \multirow[t]{2}{*}{ Author } & $\begin{array}{l}\text { No. Postoperative } \\
\text { complications }\end{array}$ & $\begin{array}{l}\text { No. Postoperative } \\
\text { complications }\end{array}$ & $\begin{array}{l}\text { Mean } \pm \text { SD Postoperative } \\
\text { Pleural Drainage }\end{array}$ & $\begin{array}{l}\text { Mean } \pm \text { SD Postoperative } \\
\text { Pleural Drainage }\end{array}$ & $\begin{array}{l}\text { Mean } \pm \text { SD } \\
\text { Hospital Stay }\end{array}$ & $\begin{array}{l}\text { Mean } \pm \text { SD } \\
\text { Hospital Stay }\end{array}$ \\
\hline & SVATS & LVATS & SVATS, $d$ & LVATS, d & SVATS & LVATS \\
\hline Suda Takashi & $2 / 46$ & $2 / 35$ & NA & NA & $4 \pm 1.5$ & $5.3 \pm 2.3$ \\
\hline Hsu C-P & $0 / 15$ & $0 / 12$ & $3.1 \pm 0.5$ & $3.8 \pm 0.6$ & NA & NA \\
\hline Wang, $\mathrm{H}$ & $5.40 \%$ & $6.70 \%$ & $1.3 \pm 0.6$ & $2.5 \pm 1.0$ & $2.2 \pm 0.9$ & $3.7 \pm 1.3$ \\
\hline Yano Motoki & $1 / 14$ & $7 / 39$ & $1.0 \pm 0$ & $1.4 \pm 0.8$ & $5.4 \pm 5.1$ & $6.6 \pm 5.7$ \\
\hline Lu Qiang & $1 / 41$ & $1 / 36$ & $1.8 \pm 1.6$ & $2.1 \pm 1.3$ & $3.6 \pm 1.3$ & $7.4 \pm 2.3$ \\
\hline Zhang Louqian & $0 / 28$ & $5 / 65$ & $0 \pm 1.0$ & $4.6 \pm 1.3$ & $3.6 \pm 1.2$ & $4.3 \pm 1.6$ \\
\hline Yong Tang & NA & NA & $1.0 \pm 0.4$ & $1.7 \pm 1.0$ & $3.8 \pm 1.1$ & $10.2 \pm 17.5$ \\
\hline
\end{tabular}

NA, not available

\section{Results}

We identified 7 references through the aforementioned search criteria [8-15]. A total of 7 studies, with publication dates ranging from 2004 to 2019, contained pertinent perioperative outcome information regarding VATS thymectomy for myasthenia gravis and thymomas. The screening process for the studies is shown in Fig. 1, and the characteristics of the included studies are summarized in Table 1. All the included articles were nonrandomized and retrospective. The total number of patients was 670; of these patients, 312 were treated with SVATS thymectomy, and 358 received LVATS thymectomy.

Demographics were calculated using the subset of 7 comparative studies, and the characteristics of the included studies are summarized in Tables 2, 3, 4 and 5 . Quality assessment of all studies was performed by using the NOS method (Table 6).

We found mean operative time to be significantly less in patients in the SVATS group than in patients in the LVATS group (119.2 versus $138.8 \mathrm{~min}$, standard difference $=-0.532,95 \%$ confidence interval $(\mathrm{CI})$ : -0.735 to $-0.329, \mathrm{p}<0.001)$, as shown in Fig. 2 . There was a significant difference between patients in the SVATS group and patients in the LVATS group about blood loss (46.8 versus $60.3 \mathrm{ml}$, standard difference $=-0.796,95 \%$ CI: -1.586 to $-0.007, p=0.048$ ), as shown in Fig. 3. Length of hospital stay was shorter for patients in the SVATS group (3.7 days for the SVSTS group versus 6.2 days for the LVATS group, standard difference $=-0.906,95 \%$ CI: -1.412 to $-0.400, p<0.001$ ), as shown in Fig. 4 . There was no significant difference between postoperative pleural drainage stay ( 1.5 days for the SVATS group versus 2.6 days for the VATS group, standard difference $=-$ 1.143, 95\% CI: -2.394 to $0.107, p=0.073$ ), as shown in Fig. 5. There was a significant difference in terms of postoperative complications (11 in the SVATS group versus 24 in the LVATS group, OR $=0.299$, 95\% CI: $0.137-0.653, p=0.002$ ), as shown in Fig. 6 . There was no significant difference between conversion to open ( 4 for the SVATS group versus 6 for the VATS group, OR $=0.482,95 \% \mathrm{CI}, 0.156$ to 2.166 , $p=0.420$ ), as shown in Fig. 7. There was no significant difference between oncologic outcomes (32 for the SVATS group versus 67 for the VATS group, $\mathrm{OR}=0.582,95 \% \mathrm{CI}, 0.142$ to $1.635, p=0.241$ ), as shown in Fig. 8.

\section{Discussion}

In this study, we observed that the statistically significant clinical outcomes were decreased operative time, blood loss, postoperative complications, and shorter hospital stay, both of which favored the SVATS

Table 4 Postoperative Outcomes

\begin{tabular}{|c|c|c|c|c|c|c|}
\hline \multirow[t]{2}{*}{ Author } & Postoperative Pain & Postoperative Pain & Radicality of the resection & Radicality of the resection & Remission of MG & Remission of $M C$ \\
\hline & SVATS & LVATS & SVATS, d & LVATS, d & SVATS & LVATS \\
\hline Suda Takashi & Low & High & RO & RO & NA & NA \\
\hline Hsu C-P & NA & NA & Ro & Ro & $6 / 15$ & $4 / 15$ \\
\hline Wang, $\mathrm{H}$ & Low & High & NA & NA & NA & NA \\
\hline Yano Motoki & NA & NA & Ro & Ro & NA & NA \\
\hline Lu Qiang & Low & High & Ro & Ro & NA & NA \\
\hline Zhang Louqian & Low & High & NA & NA & - & - \\
\hline Yong Tang & NA & NA & - & - & NA & NA \\
\hline
\end{tabular}

$\mathrm{NA}$, not available 
Table 5 Summary of Oncologic outcomes

\begin{tabular}{|c|c|c|c|c|c|c|c|c|c|c|}
\hline \multirow[b]{2}{*}{ Study } & \multicolumn{5}{|l|}{ SVATS } & \multicolumn{5}{|l|}{ LVATS } \\
\hline & Thymoma & $\begin{array}{l}\text { Tumor } \\
\text { diameter }(\mathrm{cm})\end{array}$ & Masaoka staging & MG & Carcinoma & Thymoma & $\begin{array}{l}\text { Tumor } \\
\text { diameter (cm) }\end{array}$ & Masaoka staging & MG & Carcinoma \\
\hline Suda Takashi & $11 / 46$ & NA & $\begin{array}{l}\text { Stage } \\
\text { | and || }\end{array}$ & $11 / 46$ & $0 / 46$ & $27 / 35$ & NA & $\begin{array}{l}\text { Stage } \\
\text { | and || }\end{array}$ & $10 / 35$ & $0 / 35$ \\
\hline Hsu C-P & $4 / 11$ & $\leq 4 \mathrm{~cm}$ & $\begin{array}{l}\text { Stage } \\
\text { | and || }\end{array}$ & $15 / 15$ & $0 / 15$ & $2 / 10$ & $\leq 4 \mathrm{~cm}$ & $\begin{array}{l}\text { Stage } \\
\text { | and || }\end{array}$ & $12 / 12$ & $0 / 12$ \\
\hline Wang, $\mathrm{H}$ & $36 / 36$ & NA & $\begin{array}{l}\text { Stage } \\
\text { I and || }\end{array}$ & $0 / 36$ & NA & $47 / 47$ & NA & $\begin{array}{l}\text { Stage } \\
\text { | and || }\end{array}$ & $0 / 47$ & NA \\
\hline Yano Motoki & $7 / 14$ & $4.5 \pm 2.7$ & NA & $1 / 14$ & $2 / 14$ & $26 / 46$ & NA & NA & $2 / 46$ & $2 / 46$ \\
\hline Lu Qiang & $10 / 31$ & $\leq 5 \mathrm{~cm}$ & $\begin{array}{l}\text { Stage } \\
\text { | and || }\end{array}$ & $41 / 41$ & $0 / 41$ & $12 / 24$ & $\leq 5 \mathrm{~cm}$ & $\begin{array}{l}\text { Stage } \\
\text { | and || }\end{array}$ & $36 / 36$ & $0 / 36$ \\
\hline Zhang Louqian & $28 / 28$ & $3.2 \pm 1.6$ & $\begin{array}{l}\text { Stage } \\
\text { | and || }\end{array}$ & $0 / 28$ & NA & $70 / 70$ & $3.6 \pm 1.3$ & $\begin{array}{l}\text { Stage } \\
\text { | and || }\end{array}$ & $0 / 70$ & NA \\
\hline Yong Tang & NA & NA & NA & $20 / 20$ & NA & 25 & NA & NA & $25 / 25$ & NA \\
\hline
\end{tabular}

group. We found no differences in postoperative pleural drainage stay and conversion to open between the two groups. Most studies showed that SVATS have less pain after surgery than LVATS [8, 9, 13, 15]. Our results indicate that SVATS may be a better choice for thymectomy.

In LVATS thymectomy, surgeons may encounter a poor view of mediastinal fat and phrenic nerve at the contralateral side, and it is almost impossible to obtain adequate removal of the mediastinal fat on the contralateral side $[16,17]$. Comparing to LVATS, SVATS can provide better surgical views in the upper pole of thymus and bilateral phrenic nerves $[11,18,19]$, which might reduce the incidental injury, and this is essential for adequate bilateral mediastinal fatty tissue dissection. Although the bilateral approach provided adequate exposure of the anterior mediastinum, a higher number of incisions is needed, which may increase operative trauma [17]. Our findings on shorter hospital stay and less blood loss agree with those reported by Suda et al., who encourage surgeons to try this approach as one method of performing VATS thymectomy [13]. This study only included patients with thymoma, Masaoka phase I and II, so both methods can achieve R0 resection [9, 10, 12, 13].

However, all studies about subxiphoid VATS are small-scale and retrospective, further large-scale prospective study is necessary to confirm the benefit of SVATS. Our meta-analysis was limited by the inclusion of only nonrandomized, retrospective studies. Besides, there is a paucity of long-term follow-up data for patients who have undergone thymectomy for myasthenia gravis and thymomas. Our analysis was constrained by the inability to perform propensity matching because of small aggregate sample size and difficulty in obtaining individual patient information from the included studies. These factors led to increased heterogeneity within the analysis. In the end, we need to consider another factor that whether to have a total thymectomy or a subtotal thymectomy or a partial thymectomy. We mostly advocate total thymectomy in all cases of myasthenia gravis and thymomas.

Table 6 Assessment of study quality

\begin{tabular}{|c|c|c|c|c|c|c|c|c|c|c|}
\hline \multirow[t]{3}{*}{ Study } & \multicolumn{9}{|c|}{ Quality indicators from the Newcastle-Ottawa scale } & \multirow[t]{3}{*}{ Score } \\
\hline & \multicolumn{4}{|c|}{ Selection } & \multicolumn{2}{|c|}{ Comparability } & \multicolumn{3}{|c|}{ Exposure/Outcome } & \\
\hline & 1 & 2 & 3 & 4 & $5 a$ & $5 b$ & 6 & 7 & 8 & \\
\hline Suda Takashi [13] & Yes & Yes & No & Yes & Yes & Yes & Yes & Yes & Yes & 8 \\
\hline Hsu C-P [12] & Yes & Yes & No & Yes & Yes & No & Yes & Yes & Yes & 7 \\
\hline Wang, $\mathrm{H}[15]$ & Yes & Yes & No & Yes & Yes & Yes & Yes & Yes & Yes & 8 \\
\hline Yano Motoki [10] & Yes & Yes & No & Yes & Yes & Yes & Yes & Yes & Yes & 8 \\
\hline Lu Qiang [9] & Yes & Yes & No & Yes & Yes & Yes & Yes & Yes & Yes & 8 \\
\hline Zhang Louqian [8] & Yes & Yes & No & Yes & Yes & Yes & Yes & Yes & Yes & 8 \\
\hline Yong Tang [14] & Yes & Yes & No & Yes & Yes & No & Yes & Yes & Yes & 7 \\
\hline
\end{tabular}




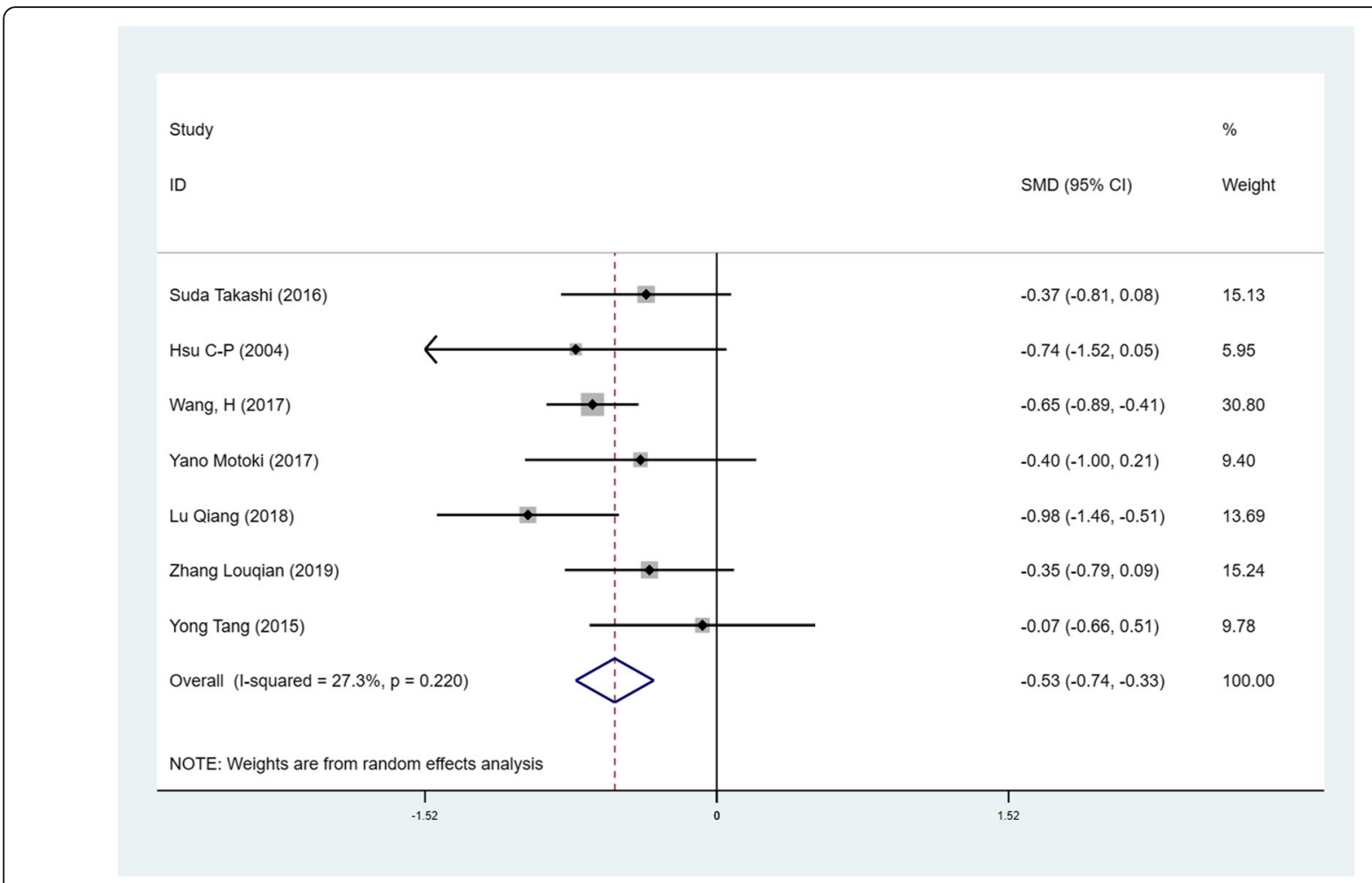

Fig. 2 SVATS versus LVATS thymectomy, operative time (minutes)

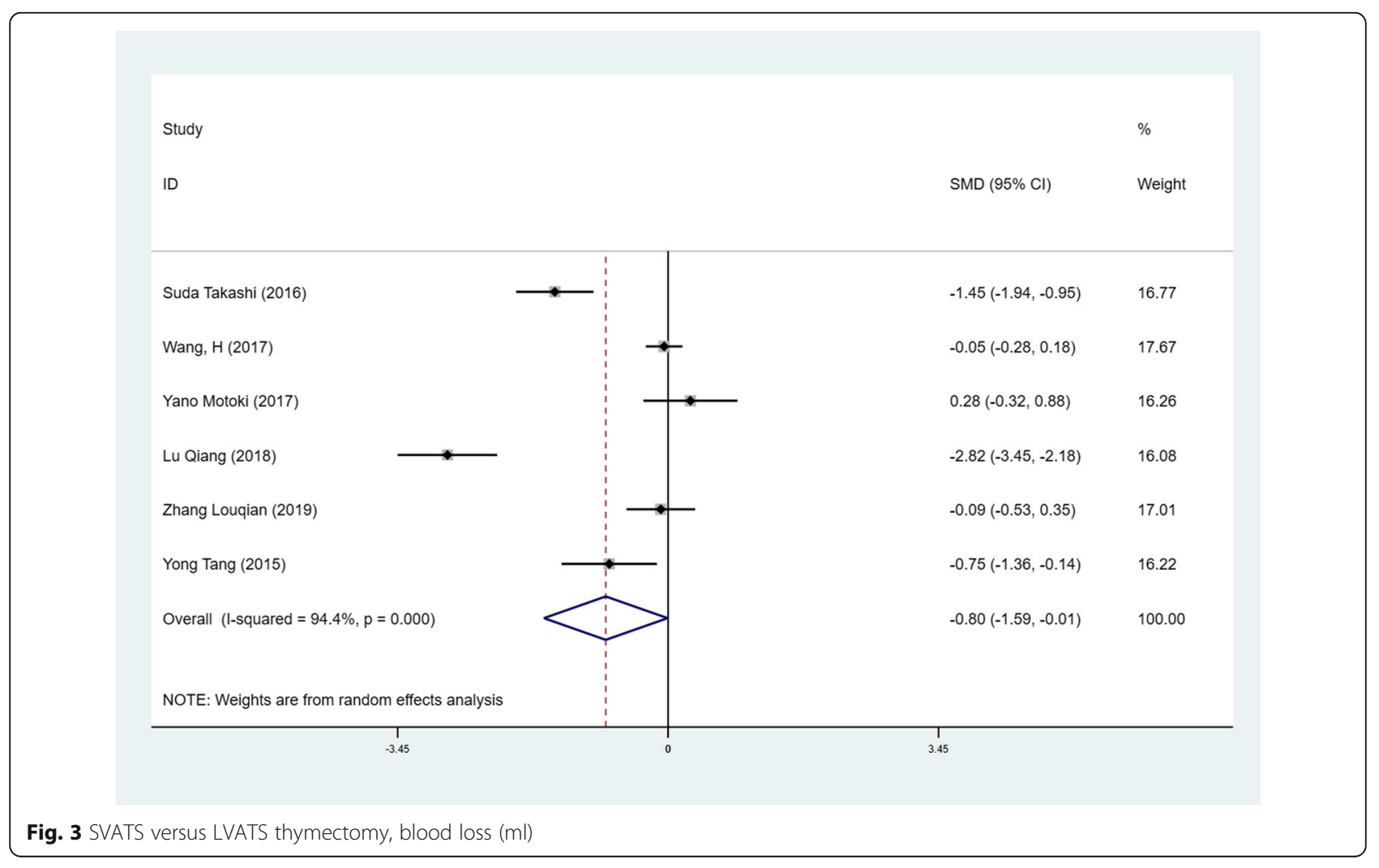




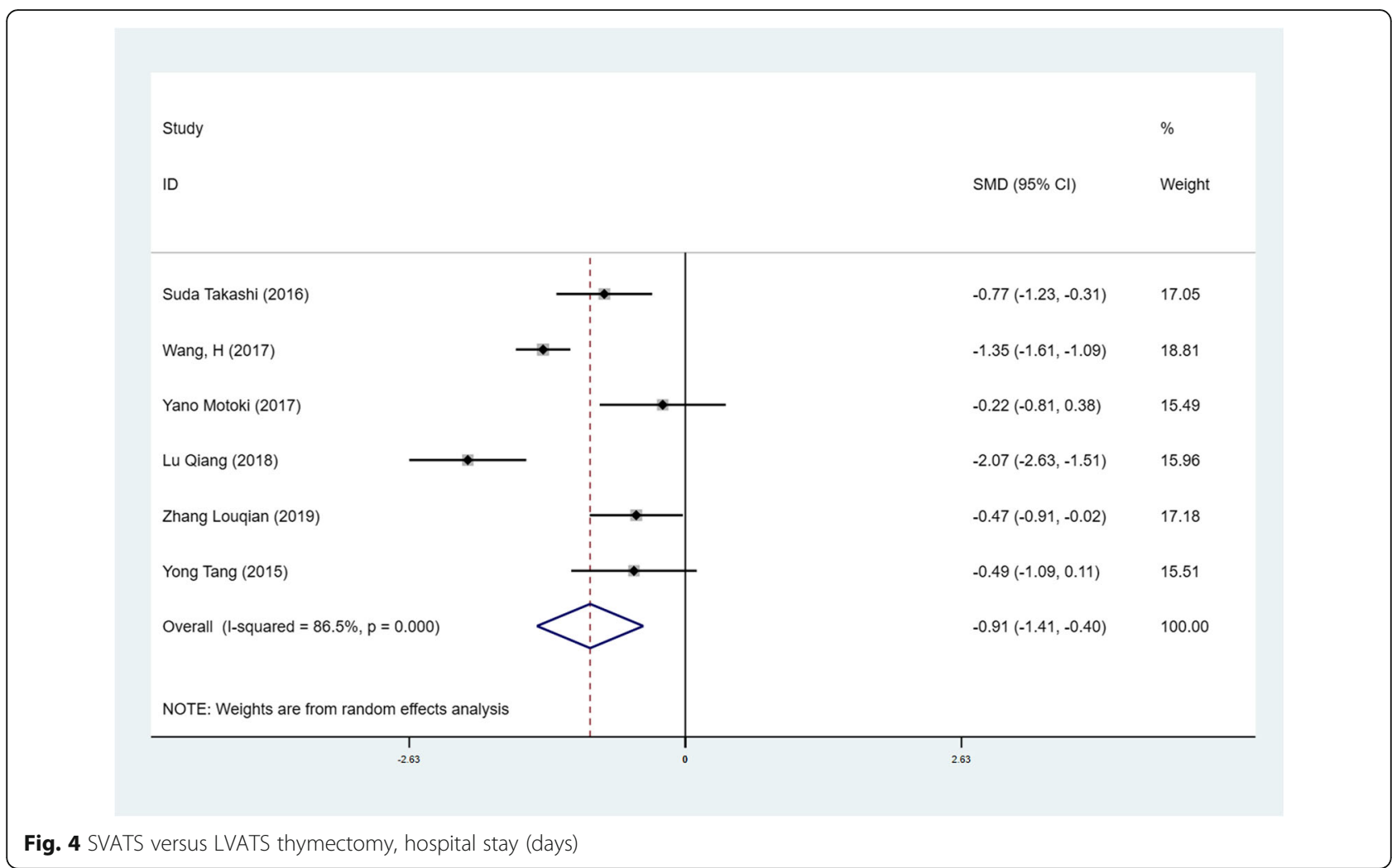

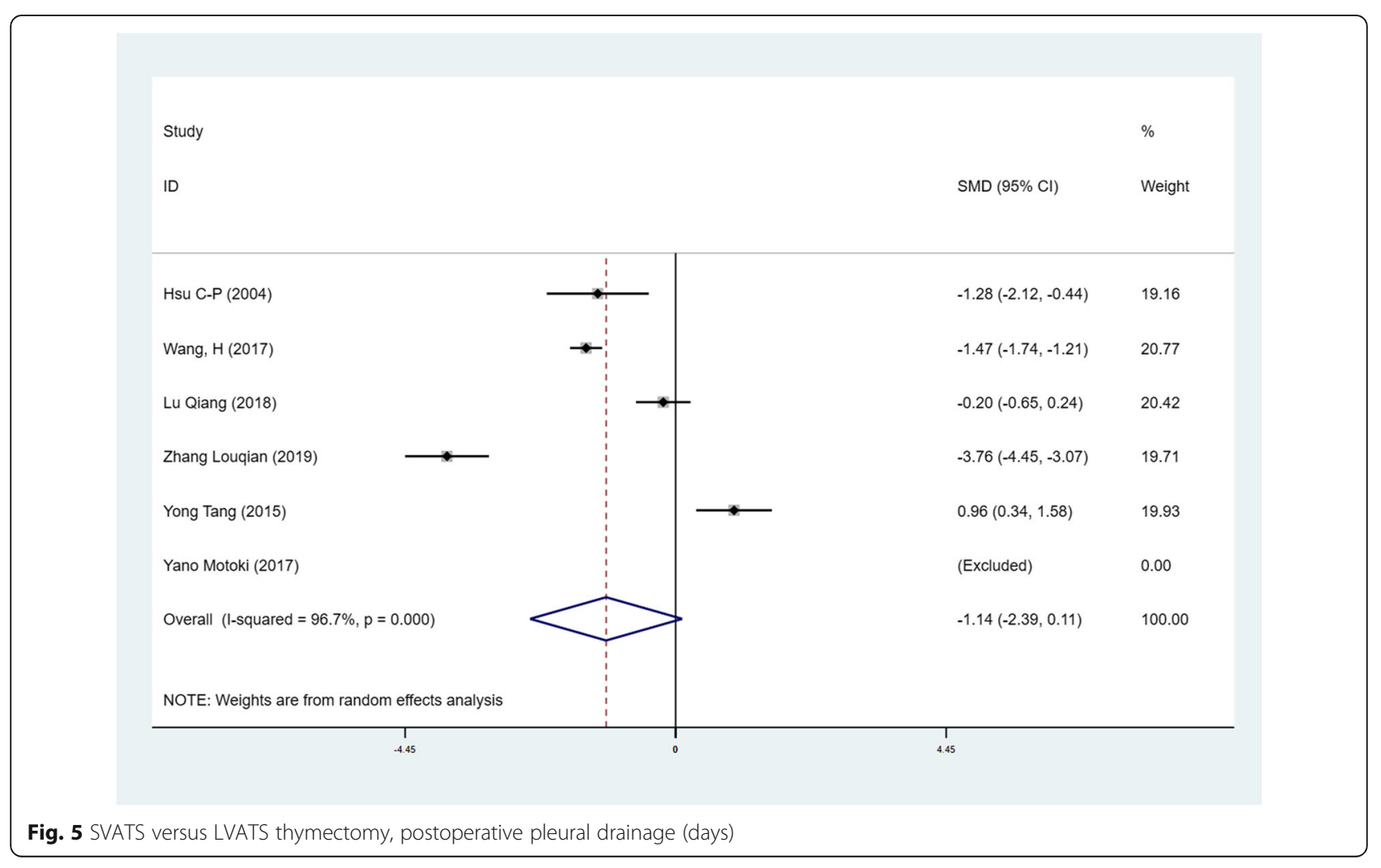


Study

ID
$\%$

OR $(95 \% \mathrm{Cl}) \quad$ Weight

$0.20(0.07,0.55) \quad 57.46$

$0.43(0.05,3.82) \quad 12.71$

$0.88(0.05,14.51) \quad 7.71$

$0.21(0.01,3.91) \quad 7.09$

(Excluded) $\quad 0.00$

$0.30(0.14,0.65) \quad 100.00$

Fig. 6 SVATS versus LVATS thymectomy, postoperative complications

Study

Lu Qiang (2018)

Suda Takashi (2016)

Hsu C-P (2004)

Yano Motoki (2017)

Zhang Lougian (2019)

Overall (I-squared $=0.0 \%, p=0.558)$

NOTE: Weights are from random effects analysis
OR $(95 \% \mathrm{Cl}) \quad$ Weight

$\begin{array}{ll}0.90(0.13,6.51) & 44.30 \\ 0.41(0.07,2.39) & 55.70 \\ \text { (Excluded) } & 0.00 \\ \text { (Excluded) } & 0.00 \\ \text { (Excluded) } & 0.00 \\ \text { (Excluded) } & 0.00 \\ 0.58 \text { (0.16, 2.17) } & 100.00 \\ \end{array}$

Fig. 7 SVATS versus LVATS thymectomy, conversion to open 


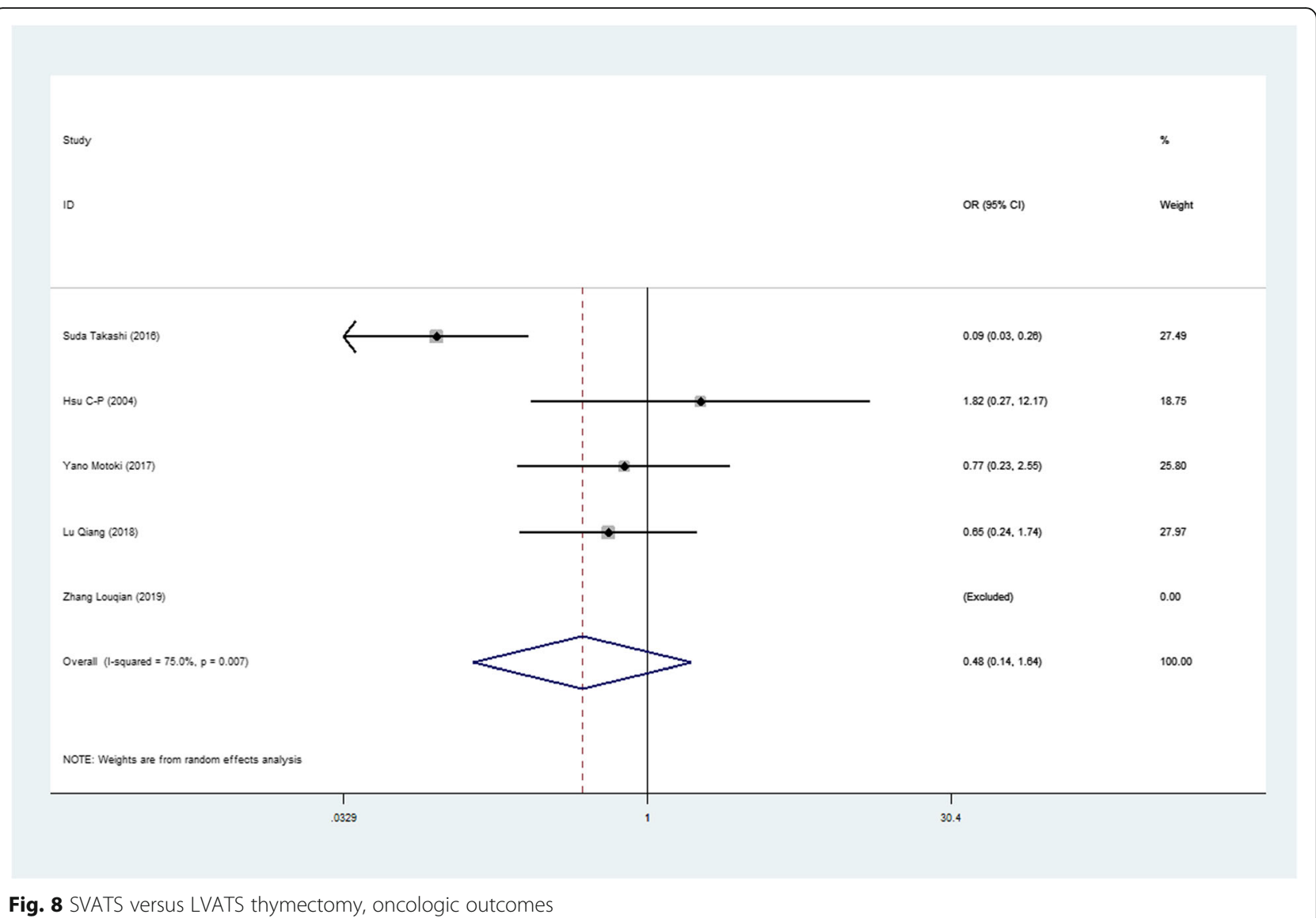

\section{Conclusion}

Based on the findings of this meta-analysis, we conclude that for selected patients, SVATS thymectomy is safe and may achieve better perioperative outcomes to those of LVATS thymectomy operations.

\section{Abbreviations}

VATS: video-assisted thoracoscopic surgery; SVATS: subxiphoid video-assisted thoracoscopic surgery; LVATS: lateral video-assisted thoracoscopic surgery; MG: myasthenia gravis

\section{Acknowledgments}

Not applicable.

\section{Authors' contributions}

$J$ put forward the idea and designed the research; All authors have made important contributions to literature searching, data extraction and analysis; \lrcorner wrote the manuscript; GY revised the manuscript; All authors approved the final version of the manuscript.

\section{Funding}

Not applicable.

\section{Availability of data and materials}

The datasets generated and analyzed during the current study are available from the corresponding author on reasonable request.

Ethics approval and consent to participate Not applicable.
Consent for publication

Not applicable.

\section{Competing interests}

Not applicable.

\section{Author details}

${ }^{1}$ Center of Treatment of Myasthenia Gravis Hebei Province, First Hospital of Shijiazhuang, Fangbei road No. 9, Shijiazhuang 050011, Hebei Province, China. ${ }^{2}$ Department of Gastroenterology, First Hospital of Shijiazhuang, Shijiazhuang, China.

Received: 28 November 2019 Accepted: 4 May 2020 Published online: 12 May 2020

\section{References}

1. Tomulescu V, Sgarbura O, Stanescu C, Valciu C, Campeanu A, Herlea V, Popescu I. Ten-year results of thoracoscopic unilateral extended thymectomy performed in nonthymomatous myasthenia gravis. Ann Surg. 2011;254:761-5; discussion 765-6. https://doi.org/10.1097/SLA. Ob013e31823686f6

2. Yu L, Zhang X-J, Ma S, Li F, Zhang Y-F. Thoracoscopic thymectomy for myasthenia gravis with and without thymoma: a single-center experience. Ann Thorac Surg. 2012;93:240-4. https://doi.org/10.1016/j.athoracsur.2011.04. 043.

3. Suda T, Ashikari S, Tochii D, Tochii S, Takagi Y. Dual-port thymectomy using subxiphoid approach. Gen Thorac Cardiovasc Surg. 2014;62:570-2. https:// doi.org/10.1007/s11748-013-0337-y

4. Ye B, Li W, Ge X-X, Feng J, Ji C-Y, Cheng M, et al. Surgical treatment of early-stage thymomas: robot-assisted thoracoscopic surgery versus transsternal thymectomy. Surg Endosc. 2014;28:122-6. https://doi.org/10. 1007/s00464-013-3137-7. 
5. Wells GA, Shea BJ, O'Connell D, Peterson J, Tugwell P. The NewcastleOttawa scale (NOS) for assessing the quality of non-randomized studies in meta-analysis; 2000.

6. Higgins JPT, Thomas J, Chandler J, Cumpston M, Li T, Page MJ, Welch VA. editors. Cochrane Handbook for Systematic Reviews of Interventions. 2nd Edition. Chichester: Wiley; 2019.

7. Hozo SP, Djulbegovic B, Hozo I. Estimating the mean and variance from the median, range, and the size of a sample. BMC Med Res Methodol. 2005;5:13. https://doi.org/10.1186/1471-2288-5-13.

8. Zhang L, Li M, Jiang F, Zhang Z, Zhang Q, Xu L. Subxiphoid versus lateral intercostal approaches thoracoscopic thymectomy for non-myasthenic early-stage thymoma: a propensity score -matched analysis. Int I Surg. 2019; 67:13-7. https://doi.org/10.1016/j.jijsu.2019.01.011

9. Lu Q, Zhao J, Wang J, Chen Z, Han Y, Huang L, et al. Subxiphoid and subcostal arch "Three ports" thoracoscopic extended thymectomy for myasthenia gravis. J Thorac Dis. 2018;10:1711-20. https://doi.org/10.21037/ jtd.2018.02.11

10. Yano M, Moriyama S, Haneda H, Okuda K, Kawano O, Oda R, et al. The subxiphoid approach leads to less invasive thoracoscopic Thymectomy than the lateral approach. World J Surg. 2017;41:763-70. https://doi.org/10.1007/ s00268-016-3783-8 .

11. Suda T, Sugimura H, Tochii D, Kihara M, Hattori Y. Single-port thymectomy through an infrasternal approach. Ann Thorac Surg. 2012;93:334-6. https:// doi.org/10.1016/..athoracsur.2011.08.047

12. Hsu C-P, Chuang C-Y, Hsu N-Y, Chen C-Y. Comparison between the right side and subxiphoid bilateral approaches in performing video-assisted thoracoscopic extended thymectomy for myasthenia gravis. Surg Endosc. 2004;18:821-4. https://doi.org/10.1007/s00464-003-9146-1 .

13. Suda T, Hachimaru A, Tochii D, Maeda R, Tochii S, Takagi Y. Video-assisted thoracoscopic thymectomy versus subxiphoid single-port thymectomy: initial resultst. Eur J Cardiothorac Surg. 2016;49(Suppl 1):i54-8. https://doi. org/10.1093/ejcts/ezv338.

14. Tang Y, Qiao G. P14. Feasibility of "subxiphoid and subcostal" approach in video-assisted thoracoscopic thymectomy for patients with myasthenia gravis. J Thorac Dis. 2015;7:P14

15. Wang H, Ding J. MA 16.06 Minimally Invasive Thoracoscopic Thymectomy for Early-Stage Thymomas: Modified Subxiphoid Approach Versus Unilateral Approach. J Thorac Oncol. 2017;12:S1868-S1869. doi:https://doi.org/10.1016/ j.jtho.2017.09.600

16. Yu L, Ma S, Jing Y, Zhang Y, Li F, Krasna MJ. Combined unilateralthoracoscopic and mediastinoscopic thymectomy. Ann Thorac Surg. 2010; 90:2068-70. https://doi.org/10.1016/j.athoracsur.2010.02.042 .

17. Nesher N, Pevni D, Aviram G, Kramer A, Mohr R, Uretzky G, et al. Videoassisted thymectomy with contralateral surveillance camera: a means to minimize the risk of contralateral phrenic nerve injury. Innovations (Phila). 2012;7:266-269. doi:https://doi.org/10.1097/IMl.0b013e3182742a53 .

18. Suda T. Single-port thymectomy using a subxiphoid approach-surgical technique. Ann Cardiothorac Surg. 2016;5:56-8. https://doi.org/10.3978/j. issn.2225-319X.2015.08.02 .

19. Chen H, Xu G, Zheng W, Chen C. Video-assisted thoracoscopic extended thymectomy using the subxiphoid approach. J Vis Surg. 2016;2:157. https:// doi.org/10.21037/jovs.2016.09.02 .

\section{Publisher's Note}

Springer Nature remains neutral with regard to jurisdictional claims in published maps and institutional affiliations.

Ready to submit your research? Choose BMC and benefit from:

- fast, convenient online submission

- thorough peer review by experienced researchers in your field

- rapid publication on acceptance

- support for research data, including large and complex data types

- gold Open Access which fosters wider collaboration and increased citations

- maximum visibility for your research: over $100 \mathrm{M}$ website views per year

At $\mathrm{BMC}$, research is always in progress.

Learn more biomedcentral.com/submissions 